\title{
AISI S1 tool steel after deep cryogenic treatment: Tensile properties and microstructure
}

\author{
Keyvan Seyedi Niaki ${ }^{1}$, Seyed Ebrahim Vahdat ${ }^{2,}$ * \\ ${ }^{1}$ Department of Mechanical Engineering, Iranian Research Organization for Science and Technology (IROST), Tehran, Iran \\ ${ }^{2}$ Department of Engineering, Ayatollah Amoli Branch, Islamic Azad University, Amol, Iran
}

Email address:

ksniaki@yahoo.com (K. S. Niaki), e.vahdat@iauamol.ac.ir (S. E. Vahdat)

\section{To cite this article:}

Keyvan Seyedi Niaki, Seyed Ebrahim Vahdat. AISI S1 Tool Steel after Deep Cryogenic Treatment: Tensile Properties and Microstructure. Advances in Materials. Special Issue: Advanced Tool Steels. Vol. 4, No. 2-1, 2015, pp. 1-8. doi: 10.11648/j.am.s.2015040201.11

\begin{abstract}
Successful employment of advanced tool steel in engineering applications is related to its ability in terms of meeting service life requirements and fabrication with proper dimensions. Deep cryogenic treatment may be used to produce advanced tool steel by simultaneously increasing toughness, strength, and hardness. Twelve sets of specimens were tested, 9 of which were deep cryogenic treated and then tempered. Tensile properties, hardness, X-ray diffraction, and scanning transmission electron microscopy were applied for macroscopic and microscopic investigations. The best results of simultaneous improvement in tensile toughness, hardness, and strength were obtained for $36 \mathrm{~h}$ soaking and $1 \mathrm{~h}$ tempering times.
\end{abstract}

Keywords: Hardness, STEM, Strength, Tensile Toughness, XRD

\section{Introduction}

Sustainable development is an important challenge in human life. It refers to changing the process of proper application of resources, conducting investments, and orienting technology development in a way that could be consistent with present and future needs. Proper use of raw materials facilitates sustainable development [1-3].

Advanced tool steel properties include high strength, wear resistance and hardness in addition to suitable toughness for enduring mechanical impact loadings. Researchers [4-9] demonstrated that sub zero treatments improved mechanical properties of several steels. For example, for AISI M2 high speed tool steel hardness and wear resistance improved by using DCT compared with the conventional treatment [6]. Therefore, DCT used in this study for producing advanced AISI S1 tool steel.

\section{Experimental methods}

Table 1 demonstrates the chemical analysis of AISI S1 used in this study. The AISI S1 is mostly used for manufacturing cutting blades for thick sheets and also for punching tools.

Table 1. Chemical analysis of the AISI S1 tool steel

\begin{tabular}{lllllllllllll}
\hline Element & (W\%) & Element & (W\%) & Element & (W\%) & Element & (W\%) & Element & (W\%) & Element & (W\%) \\
\hline $\mathrm{C}$ & 0.4800 & $\mathrm{Ni}$ & 0.1280 & $\mathrm{~S}$ & 0.0250 & $\mathrm{~W}$ & 1.5700 & $\mathrm{Mo}$ & 0.0281 & $\mathrm{Fe}$ & $\mathrm{Rest}$ \\
$\mathrm{Si}$ & 0.9950 & $\mathrm{~V}$ & 0.0148 & $\mathrm{Cr}$ & 1.1200 & $\mathrm{Mn}$ & 0.3360 & $\mathrm{P}$ & 0.0567 & & \\
\hline
\end{tabular}

Many studies have been published on advanced tool steels; however, each one has focused on one or few sets of specimens rather than collecting data from many specimens. Consequently, it is helpful to collect the published results in order to have thorough representations of the measured effects. Thus, 12 sets of AISI S1 specimens were tested. One set consisted of the specimens which underwent the conventional hardening procedure [10]. The remaining sets of specimens underwent full treatment cycles. The temperature-time history for the specimens is given in Fig. 1(a) and flowchart of the experimental procedure is depicted in Fig. 1(b). The DCT work followed a procedure shown in Fig. 1(b) and used a programmable cryogenic processor which was designed and developed [11]. Considering the 
required tempering temperature of $200^{\circ} \mathrm{C}$, the cryogenic processor had some added facility for the in-situ tempering of the DCT specimens for the required time durations. The time from the end of hardening to the beginning of DCT was $\approx 17$ min. However, the DCT specimens were tempered in-situ, which led to the minimum time gap between the steps as $\approx 2$ min. The specimens were assigned codes for easy identification, which is described in Tables 2 and 3.

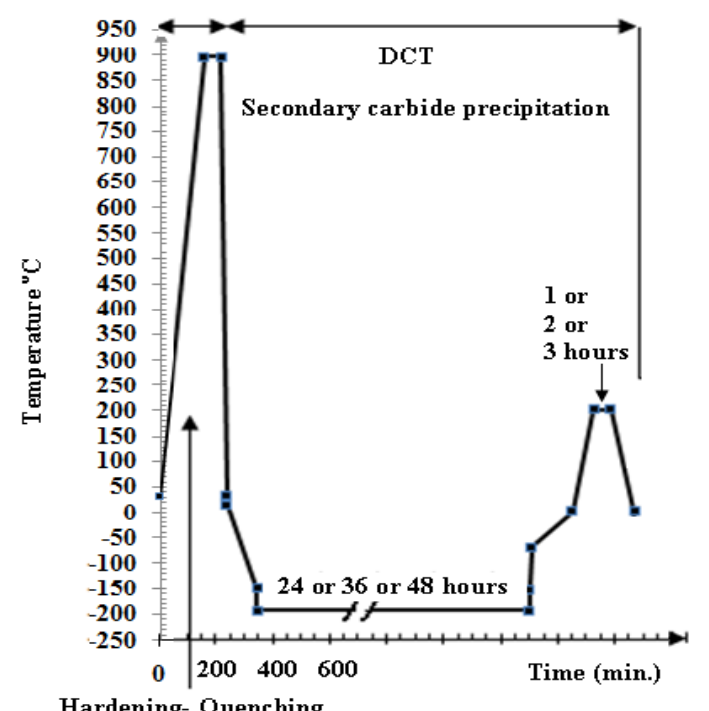

(a) DCT cycles

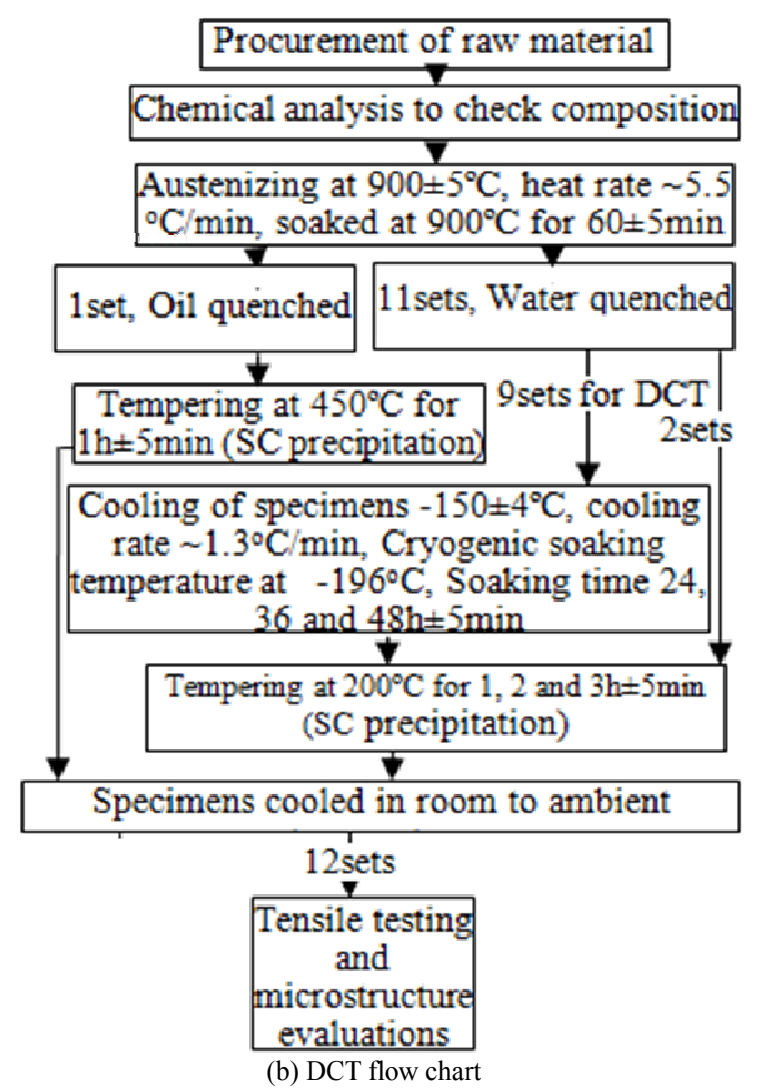

Figure 1. DCT (a) Cycles; (b) Flow chart

Table 2. Codes for hardening of the AISI S1 tool steel

\begin{tabular}{|c|c|c|c|c|c|}
\hline Code & Process & Step 1 & Step 2 & Step 3 & Tempering process \\
\hline $\begin{array}{l}\text { Standard } \\
002,003,241,242,243, \\
361,362,363,481,482,483\end{array}$ & $\begin{array}{l}\text { Oil } \\
\text { quenching } \\
\text { Water } \\
\text { quenching }\end{array}$ & $\begin{array}{l}\text { heated to } 900 \pm 5{ }^{\circ} \mathrm{C} \\
\text { (rate } \sim 5.5^{\circ} \mathrm{C} / \mathrm{min} \text { ) }\end{array}$ & $\begin{array}{l}\text { soaked at } 900{ }^{\circ} \mathrm{C} \\
\text { for } 60 \pm 5 \mathrm{~min}\end{array}$ & $\begin{array}{l}\text { quenched } \\
\text { in oil } \\
\text { quenched } \\
\text { in water }\end{array}$ & $\begin{array}{l}\text { tempered at } 450{ }^{\circ} \mathrm{C} \text { for } 1 \mathrm{~h}\left(\text { rate } \sim 3{ }^{\circ} \mathrm{C} / \mathrm{min}\right) \text { then } \\
\text { air cooled to ambient temperature } \\
\text { Continued in Table } 3\end{array}$ \\
\hline
\end{tabular}

Table 3. Codes for DCT of AISI S1 tool steel

\begin{tabular}{|c|c|c|c|c|c|c|}
\hline \multirow{2}{*}{ Code } & \multirow{2}{*}{ Cooling } & \multirow{2}{*}{$\begin{array}{l}\text { Soaking } \\
\text { temperature }\end{array}$} & \multicolumn{2}{|r|}{ Tempering } & \multirow[b]{2}{*}{ time } & \multirow{2}{*}{ Final cooling } \\
\hline & & & time & temperature & & \\
\hline 002 & ----- & -------- & ----- & \multirow{11}{*}{$\begin{array}{l}200 \pm 5^{\circ} \mathrm{C} \\
\left(\text { rate } \sim 3{ }^{\circ} \mathrm{C} / \mathrm{min}\right)\end{array}$} & $2 \mathrm{~h}$ & \multirow{11}{*}{$\begin{array}{l}\text { Cooled in room to ambient } \\
\text { temperature }\end{array}$} \\
\hline 003 & ----- & -------- & ----- & & $3 \mathrm{~h}$ & \\
\hline 241 & \multirow{9}{*}{$\begin{array}{l}-150 \pm 4{ }^{\circ} \mathrm{C} \\
\left(\text { rate } \sim 1.3^{\circ} \mathrm{C} / \mathrm{min}\right)\end{array}$} & \multirow{9}{*}{$-196 \pm 6^{\circ} \mathrm{C}$} & & & $1 \mathrm{~h}$ & \\
\hline 242 & & & $24 \mathrm{~h}$ & & $2 \mathrm{~h}$ & \\
\hline 243 & & & & & $3 \mathrm{~h}$ & \\
\hline 361 & & & & & $1 \mathrm{~h}$ & \\
\hline 362 & & & $36 \mathrm{~h}$ & & $2 \mathrm{~h}$ & \\
\hline 363 & & & & & $3 \mathrm{~h}$ & \\
\hline 481 & & & & & $1 \mathrm{~h}$ & \\
\hline 482 & & & $48 \mathrm{~h}$ & & $2 \mathrm{~h}$ & \\
\hline 483 & & & & & $3 \mathrm{~h}$ & \\
\hline
\end{tabular}

The specimens had to be machined to the required sizes prior to their treatment. The uniaxial force-displacement tensile test $(\mathrm{F}-\Delta \mathrm{L})$ was carried out on a standard specimen with $5 \mathrm{~mm}$ diameter and $25 \mathrm{~mm}$ parallel length at room temperature, according to BS EN 10002-1 [12]. The strain rate was $0.00166 \mathrm{~S}-1$, each test was repeated for three times, and the average value was obtained. For example, it depicted for specimens of 361 and 003 in Fig. 2.

A fast and reliable tool for phase and orientation map acquisition by an STEM was obtained in [13]. STEM specimens were cut out as $3 \mathrm{~mm}$ discs in the wire cut machine, thinned to $\sim 100 \mathrm{~nm}$ by hand polishing, then dimpled and argon ion milled using a Gatan PIPS mill and cold stage. STEM machine used at LeRoy Eyring Center for Solid State Science, John Cowley Center for HREM, Arizona State University, USA. Theoretical patterns calculated for the phases listed in the ASTM E975-13 [14]. 


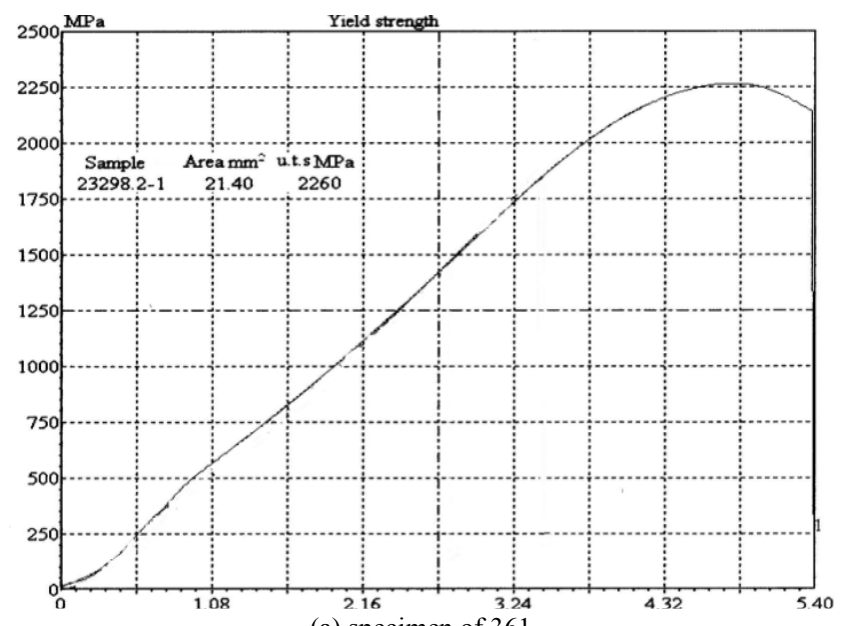

(a) specimen of 361

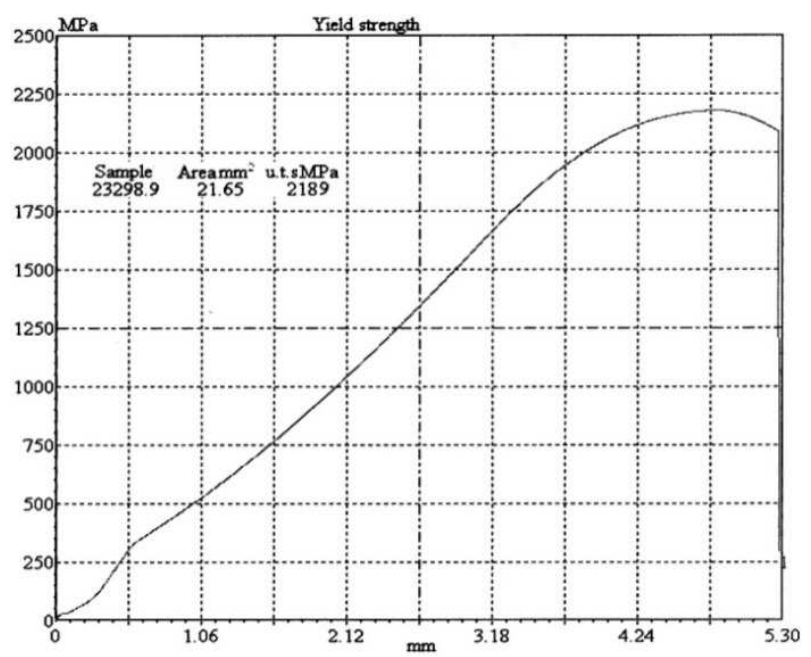

(b) specimen of 003

Figure 2. F- $\Delta L$ curve for specimens of (a) 361 and (b) 003

\section{Results and Discussion}

\subsection{Tensile Evaluations}

As shown in Figs. 3 and 4, for different specimens, yield strength and UTS showed no relative changes. However, in comparison with the standard specimen, UTS and hardness of the DCT specimens had $32-36 \%$ and $9-12 \%$ increase, respectively.

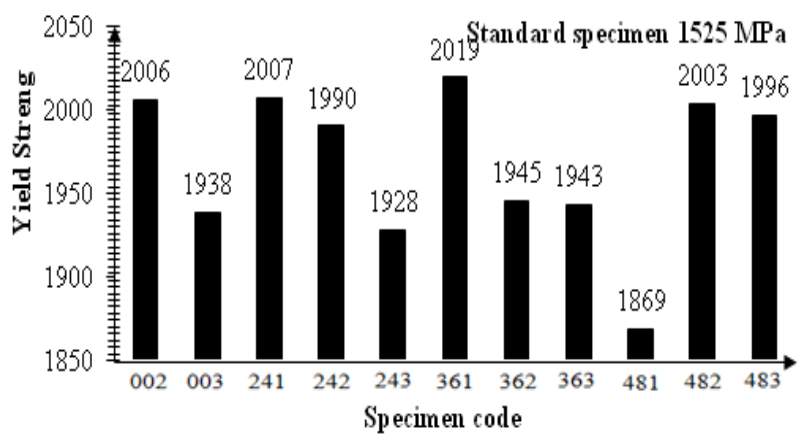

Figure 3. Tempering time trend of yield strength

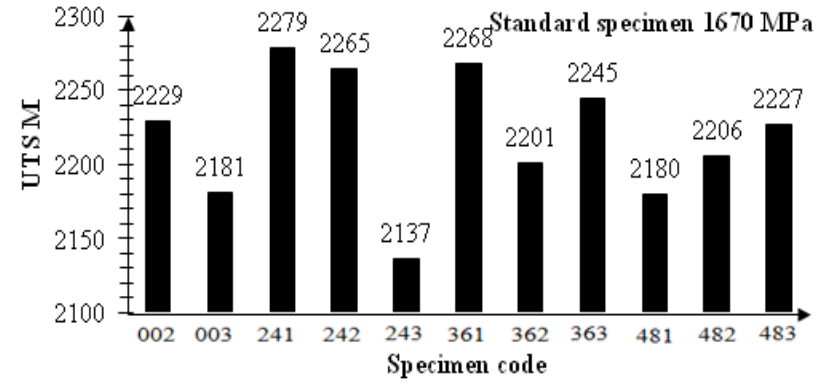

Figure 4. Tempering time trend of UTS

Fig. 5 shows that, with increasing the tempering time, the soaking time required for obtaining the maximum hardness was reduced. For example, for $1 \mathrm{~h}$ of tempering time, $48 \mathrm{~h}$ of soaking time at $-196^{\circ} \mathrm{C}$ was needed to achieve maximum hardness. For $2 \mathrm{~h}$ of tempering time, the corresponding soaking time at $-196^{\circ} \mathrm{C}$ was approximately $24 \mathrm{~h}$ and further increase in soaking time was not necessary. In other words, with increase in tempering time, shorter soaking time was required for obtaining maximum hardness. In addition, Fig. 5 demonstrates that, with increase in soaking time, the tempering time required for obtaining maximum hardness was reduced. For example, for $24 \mathrm{~h}$ of soaking time at $-196^{\circ} \mathrm{C}, 3 \mathrm{~h}$ of tempering time was needed to achieve maximum hardness. For $36 \mathrm{~h}$ of soaking time at $-196^{\circ} \mathrm{C}$, the corresponding tempering time was $2 \mathrm{~h}$. In the case of $48 \mathrm{~h}$ of soaking time, the required tempering time was $1 \mathrm{~h}$. In other words, with increase in soaking time, shorter tempering time was required for achieving maximum hardness.

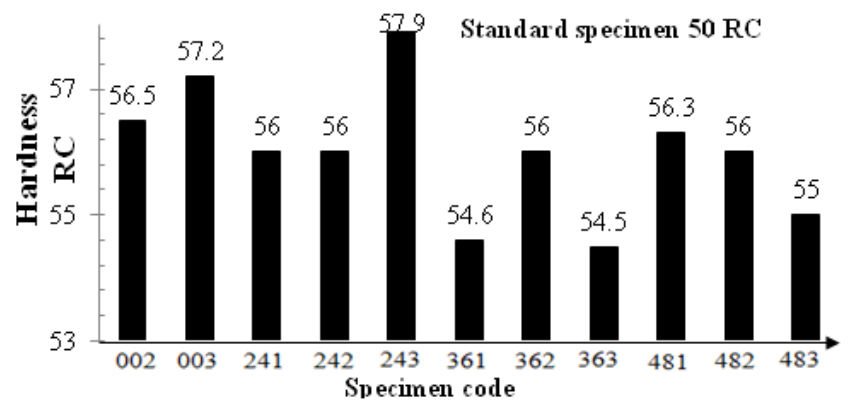

Figure 5. Tempering time trend of hardness

The above findings could be explained by the results of microstructure section. Volume fraction $\left(\mathrm{V}_{\mathrm{f}}\right)$ of SC increased with soaking or tempering times from $2.18 \mathrm{~V} \%$ to $12.87 \mathrm{~V} \%$ (Fig. 10), which led to maximum hardness.

As demonstrated in Fig. 6, among all the specimens, elongation of specimen 242 was the minimum, while specimens 361 and 482 had maximum elongation. Therefore, according to Figs. 4 and 6 and considering the following relation in [15] (Equation 1), specimens 361 and 482 presented $12-35 \%$ improvement in tensile toughness as demonstrated in Fig. 7; where UTS is ultimate tensile strength and $e_{f}$ is fracture strain.

$$
2 / 3 \times \mathrm{UTS} \times \mathrm{e}_{\mathrm{f}} \approx \mathrm{U}_{\mathrm{T}} \text { or tensile toughness }
$$




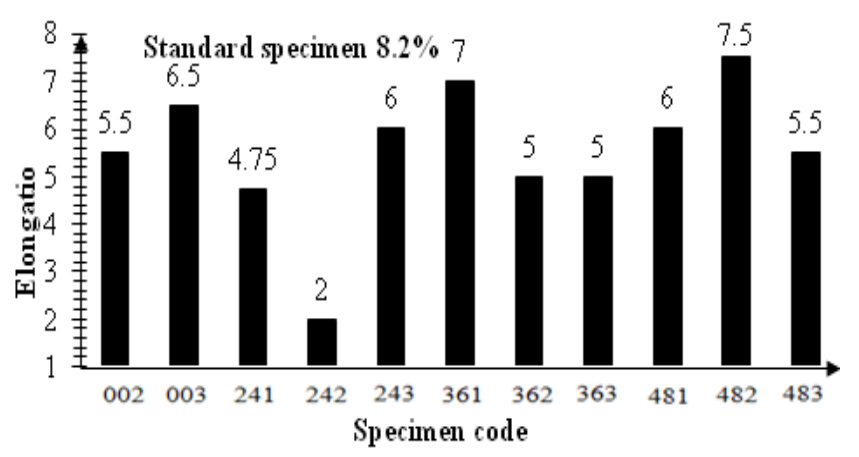

Figure 6. Tempering time trend of elongation

As demonstrated in Fig. 7, in this research, specimens 361 and 482 had higher tensile toughness than conventionally treated ones, which showed that increasing DCT duration needed increasing tempering time to obtain high tensile toughness. For example, for $36 \mathrm{~h}$ of soaking time at $-196^{\circ} \mathrm{C}, 1$ $\mathrm{h}$ of tempering time was needed to achieve maximum tensile toughness. For $48 \mathrm{~h}$ of soaking time at $-196^{\circ} \mathrm{C}$, the corresponding tempering time was $2 \mathrm{~h}$. In other words, with increase in the tempering time, longer soaking time was required for obtaining maximum tensile toughness, because tempering after DCT caused more reduction of residual stress than tempering after conventional treatment [16]. In other words, increasing DCT duration produced more dislocations $[17,18]$, which needed increasing tempering time (at constant tempering temperature) to obtain high tensile toughness.

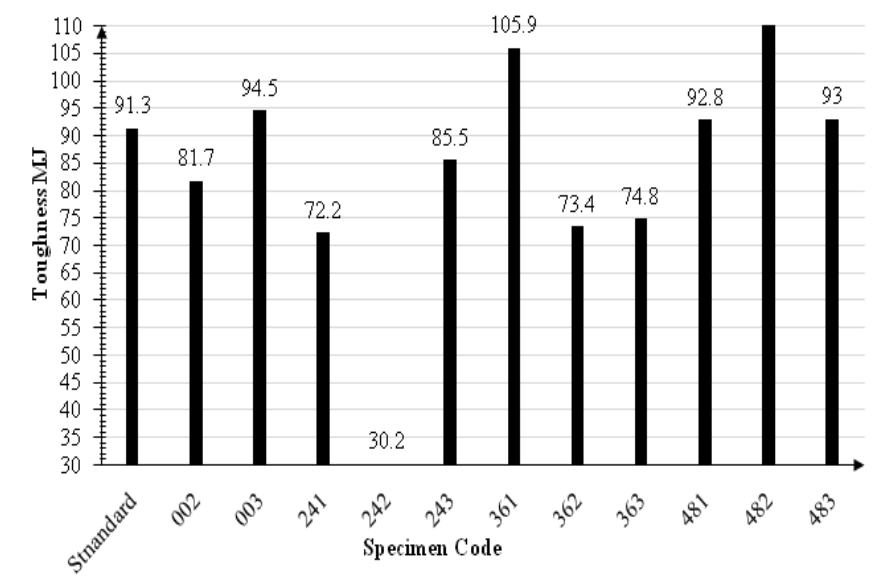

Figure 7. Tempering time trend of tensile toughness

\subsection{XRD and STEM Evaluations}

The austenite to martensite transformation $\left(\mathrm{M}_{\mathrm{s}}\right)$ started at $274.63^{\circ} \mathrm{C}$ and finished $\left(\mathrm{M}_{\mathrm{f}}\right)$ at $59.63^{\circ} \mathrm{C} \cdot \mathrm{M}_{\mathrm{s}}$ and $\mathrm{M}_{\mathrm{f}}$ values were obtained using Payson and Savage' equations (2) and (3) [19], which were valid for AISI S1.

$$
\begin{gathered}
\mathrm{M}_{\mathrm{s}}\left({ }^{\circ} \mathrm{C}\right)=498.9-(316.7 \times \mathrm{C} \%)-(33.3 \times \mathrm{Mn} \%)-(27.8 \times \mathrm{Cr} \%)- \\
(16.7 \times \mathrm{Ni} \%-11.1 \times(\mathrm{Si}+\mathrm{Mo}+\mathrm{W})) \\
\left.\mathrm{M}_{\mathrm{f}}\left({ }^{\circ} \mathrm{C}\right)=\mathrm{M}_{\mathrm{s}}{ }^{\circ} \mathrm{C}\right)-215
\end{gathered}
$$

Therefore, at $-196^{\circ} \mathrm{C}$, the retained austenite was completely transformed into martensite, which confirmed the results from $\mathrm{Cu} \mathrm{K} \alpha$ radiation diffraction (XRD) phase analysis PHLIPS at 40KV. As demonstrated in Fig. 8 for specimens 002 and 483, the retained austenite was not observed.
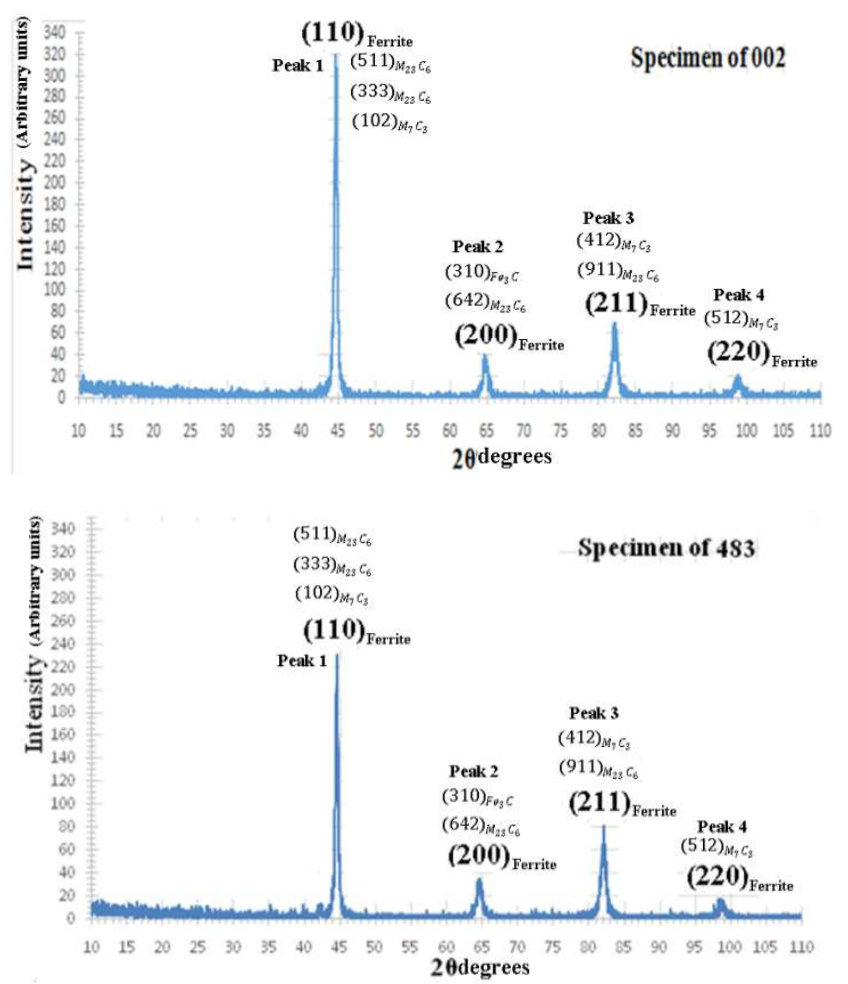

Figure 8. Diffraction of $\mathrm{Cu}$ Ka ray after processing for specimens of 002 and 483

Fig. 9(a) shows that there was no dislocation around the carbide particles. Also, EDS analysis showed this particle was iron carbide. Iron carbide diffraction patterns were sensed near the retained austenite grains; but, there was no compositional signal.

Fig. 9(b) demonstrates spherical shape carbides with sub-micron sizes. Also, SCs were dispersed, as can be seen in this low magnification micrograph.

Fig. 9(c) shows STEM map of $\mathrm{M}_{7} \mathrm{C}_{3}, \mathrm{M}_{23} \mathrm{C}_{6}, \mathrm{Fe}_{3} \mathrm{C}, \mathrm{M}_{6} \mathrm{C}$, and $\mathrm{Cr}_{3} \mathrm{C}_{2}$ carbides and retained austenite in the ferrite matrix, which was taken from the same area of about $80000 \mathrm{~nm}^{2}$. This method detected new carbides $\left(\mathrm{Fe}_{3} \mathrm{C}, \mathrm{M}_{6} \mathrm{C}\right.$ and $\left.\mathrm{Cr}_{3} \mathrm{C}_{2}\right)$ which could not be detected by SEM in the previous research [17]. According to the second mechanism of precipitation of carbides (SCs or TCs) [17], during DCT, there would be appropriate places around PCs for the precipitation of carbides (SCs or TCs). At low tempering temperature, diffusion was more difficult. So, the question is: how does it work? First, diffusion coefficient of carbon is higher than alloying element ones (such as $\mathrm{W}$ and $\mathrm{Cr}$ ). Second, in grain boundaries, diffusion coefficient is higher than that inside the grains. All of these points would lead to the facilitated precipitation of carbides (SCs or TCs) around the PCs in grain boundaries. 


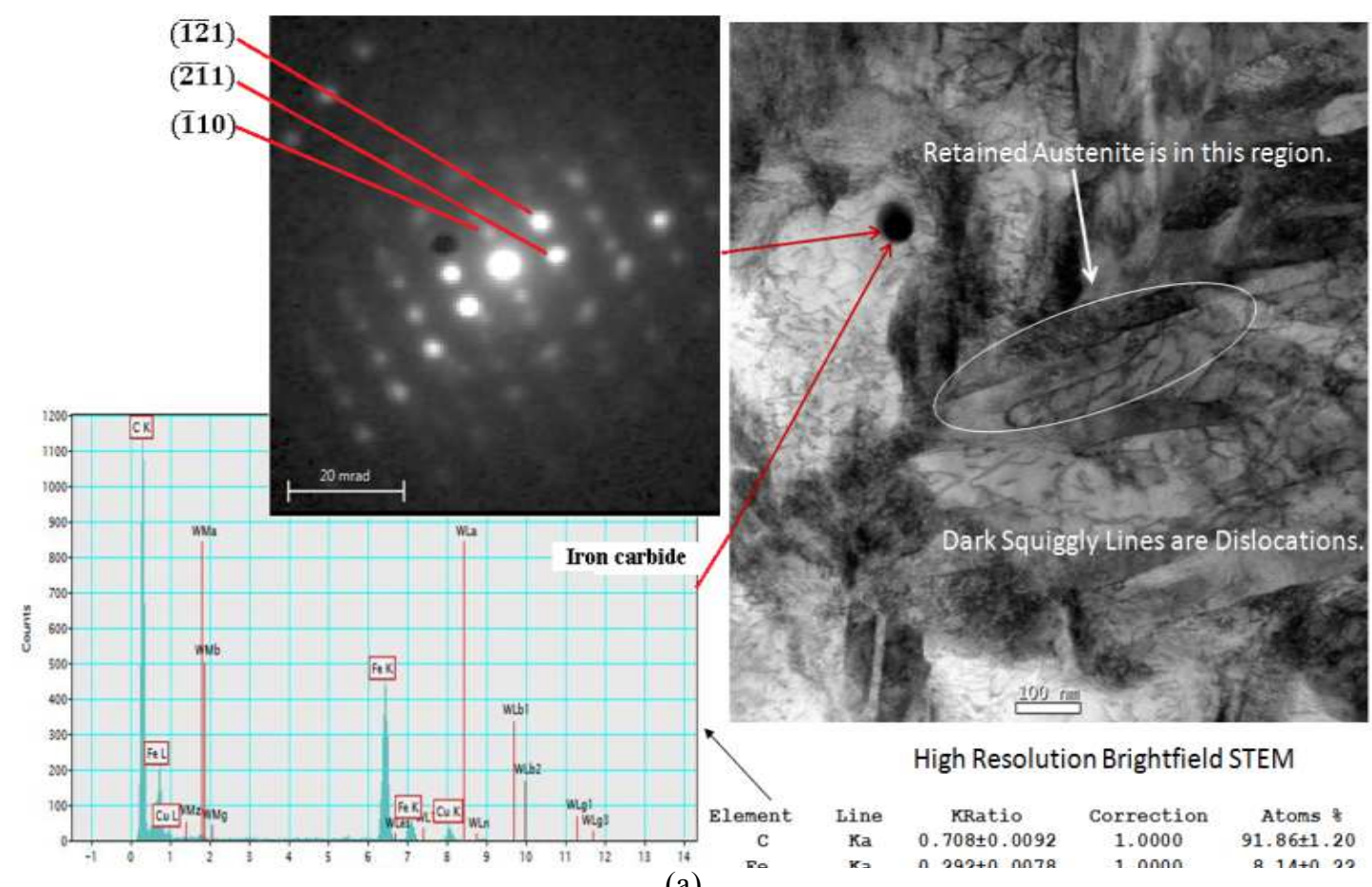

(a)
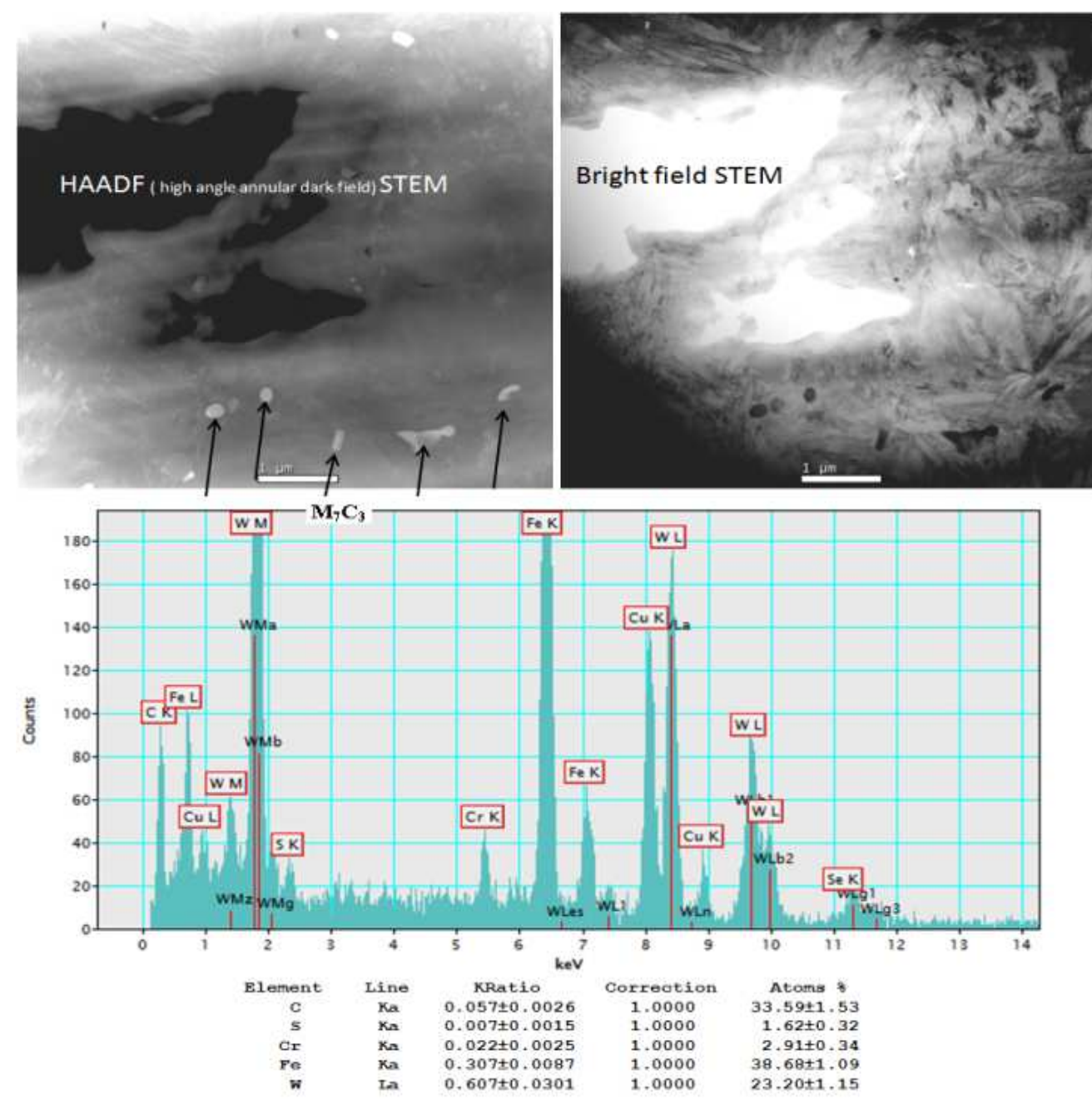

(b) 


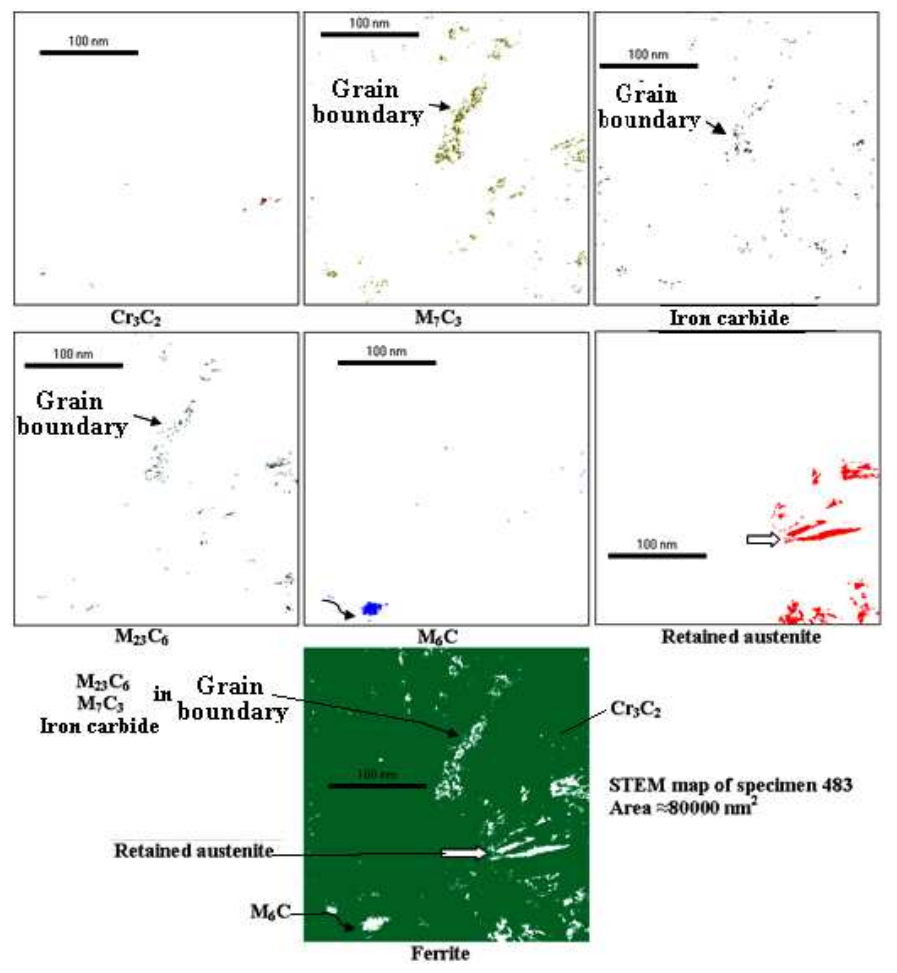

(c)

Figure 9. Morphology and size of phases by using STEM (a) dislocations (dark squiggly lines), retained austenite region and carbide (black circle) (b) carbides (grey) (c) STEM map of specimen of 483

As depicted in Fig. 10, volume fraction of the PC was approximately constant $(\approx 0.4 \pm 0.2 \mathrm{~V} \%)$ in different specimens, while Fig. 10 demonstrates that volume fraction of the SC increased with soaking or tempering times from $2.18 \mathrm{~V} \%$ to $12.87 \mathrm{~V} \%$. As represented in Fig. 10, an increase in soaking time resulted in the precipitation of more SC $(500 \%$ on average) due to dislocation density around the PCs in phase matrix, which increased with an increase in the soaking time and facilitated SC precipitation. It can be observed in Fig. 10 that an increase in tempering time resulted in the slight precipitation of SC (on average $50 \%$ ). On the other hand, volume fraction of SC in specimens 002 and 003 was somehow fixed, since, without carrying out DCT, the conditions for the formation of SC were not facilitated.

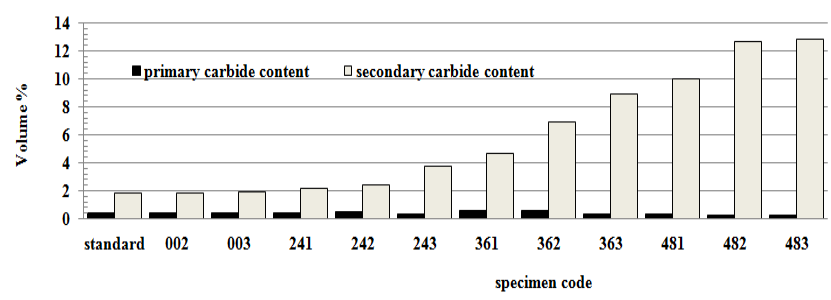

Figure 10. $P C$, SC volume fraction

According to Fig.11, population density (PD) of PC was constant for all the specimens. Also, Fig. 12 shows that average size of the PC remained almost constant with increase in soaking or tempering times (especially, for long soaking times of $48 \mathrm{~h}$, for example), which was the specifications of PC depending on the austenitization treatment parameters that were kept constant in this research.

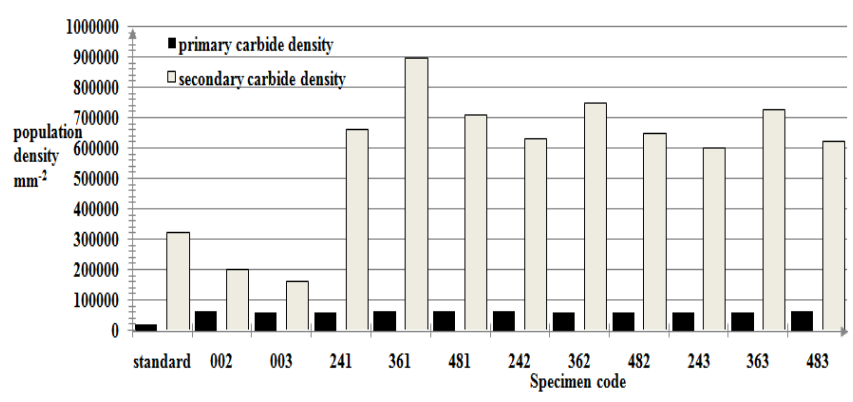

Figure 11. PD of the PCs and SCs

According to Fig. 11, in the specimens with similar soaking times, PD of SC was reduced with increase in the tempering time, which was due to the fact that, for the same soaking time, density of the dislocation which was made during the process was almost the same. Therefore, with an increase in tempering time, growth of SCs would take place owing to their joining because of relatively shorter distance.

As shown in Fig. 12, with increase in the tempering time, size of SC had a slight increase (up to 13.6\%). Similarly, according to Fig. 12, with an increase in the soaking time, size of SC also increased (up to $100 \%$ ) due to the increase in dislocation density. Additionally, lattice distortion in the regions surrounding SC was relatively higher due to the relatively less reduction in the alloy elements and carbon content owing to being utilized in the precipitation of relatively fine SC.

Comparative assessment of the characteristics of SCs of 
specimen 361 and those of specimens 002 and 003 could help infer that volume fraction of SCs increased by $125 \%$ (Fig. 10) and PD of SCs increased by $350 \%$ (Fig. 11) which was associated with reduction in their mean diameter by $30 \%$ (Fig. 12). These results unambiguously indicated that DCT refined SCs.

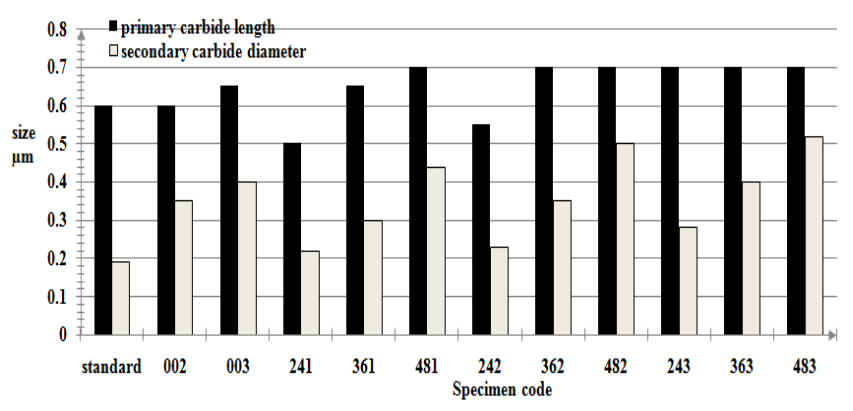

Figure 12. Average size of the PCs and SCS

\section{Conclusions}

Different soaking and tempering times were considered to study the effect of various treatment cycles on tensile properties and microstructure of advanced AISI S1 specimens. Kinetically, in the present research, the most appropriate times were $36 \mathrm{~h}$ and $48 \mathrm{~h}$ of deep cryogenic and $1 \mathrm{~h}$ and $2 \mathrm{~h}$ of tempering treatments, respectively, because $12-35 \%$ improvement in tensile toughness, 9-12\% improvement in hardness, and 32-36\% improvement in strength were obtained at these times. For advanced AISI S1 steel, it was observed that maximum tensile toughness could be obtained by simultaneously increasing soaking and tempering times. But, if reduction in production time and cost was of primary concern, lower soaking and tempering times would seem to be a more feasible option. In this case, $36 \mathrm{~h}$ of soaking time and 1 $\mathrm{h}$ of tempering time would be a more feasible option.

\section{Nomenclature}

$\begin{array}{ll}\text { DCT } & \begin{array}{l}\text { Deep Cryogenic Treatment } \\ \text { PD }\end{array} \\ \text { PC } & \begin{array}{l}\text { Primalation Density } \\ \text { Carbide precipitates as the consequence of the } \\ \text { solidification }\end{array} \\ & \begin{array}{l}\text { Secondary Carbide } \\ \text { Carbide precipitates as the consequence of the } \\ \text { first tempering }\end{array} \\ \text { SC } & \text { Scanning Electron Microscopy } \\ \text { SEM } & \text { Scanning Transmission Electron Microscopy } \\ \text { STEM } & \text { Volume Fraction } \\ \text { Vf } & \text { X-ray diffraction } \\ \text { XRD } & \end{array}$

\section{References}

[1] S. E. Vahdat and A. Pournaghi, "The Model for Monitoring of Pollutants Located in Different Regions," Management Science and Practice Vol. 1, pp. 8-13, 2013.
[2] S. E. Vahdat and F. M. Nakhaee, Eds., Air Pollution Monitoring using Fuzzy Logic in Industries, (InTech, Croatia, 2011), pp. 21-30.

[3] S. E. Vahdat and N. Towhidi, "Sustainable development of Iron and steel making in Environment in Iran by fuzzy logic," Journal of Environmental Studies Vol. 51, pp. 111-122, 2009.

[4] Q. Wang, X. Ning, Q. Chen and B. Mao, Eds., Effect of Cryogenic Treatment on Retained Austenite and Fatigue Life of Gcr15 Wheel-Hub Bearing, (Springer Berlin Heidelberg, 2013), vol. 196, pp. 1701-1707.

[5] S. Katoch, R. Sehgal and V. Singh, Eds., Effect of Cryogenic Treatment on Hardness, Microstructure and Wear Behavior of Hot Die Steel Grade AISI-H13, (Springer India, 2014), pp. 159-166.

[6] S. Gill, J. Singh, R. Singh and H. Singh, "Effect of Cryogenic Treatment on AISI M2 High Speed Steel: Metallurgical and Mechanical Characterization," J. of Materi Eng and Perform Vol. 21, pp. 1320-1326, 2012.

[7] S. Gill and H. Singh, Eds., Cryogenic Treatment of Materials: Cutting Tools and Polymers, (Springer Berlin Heidelberg, 2013), pp. 245-273.

[8] S. Gill, J. Singh, R. Singh and H. Singh, "Metallurgical principles of cryogenically treated tool steels - a review on the current state of science," Int J Adv Manuf Technol Vol. 54, pp. 59-82, 2011.

[9] S. Gill, H. Singh, R. Singh and J. Singh, "Cryoprocessing of cutting tool materials - a review," Int J Adv Manuf Technol Vol. 48, pp. 175-192, 2010.

[10] C. W. Wegst, Key to Steel, (Verlag Stahlschlussel Wegst GMBH, Dusseldorf, 1989).

[11] F. Farhani and K. S. Niaki, "A Programmable System for Treatment of Alloy Steels at Cryogenic Temperatures," Advanced Materials Research Vol. 264-265, pp. 1240-1245, 2011.

[12] B.S., 10002-1, Metallic materials tensile testing, Part 1: method of test at ambient temperature, 2001

[13] S. Thuillier and E. F. Rauch, "Development of microbands in mild steel during cross loading," Acta Metallurgica et Materialia Vol. 42, pp. 1973-1983, 1994.

[14] A.S.T.M., E975, X-Ray Determination of Retained Austenite in Steel with Near Random Crystallographic Orientation, 2013

[15] G. E. Dieter, Ed., Mechanical Behavior under tensile and compressive loads, (ASM international, Ohio, 2000), vol. 8, pp. $5,100-103$.

[16] A. Bensely, S. Venkatesh, D. Mohan Lal, G. Nagarajan, A. Rajadurai and K. Junik, "Effect of cryogenic treatment on distribution of residual stress in case carburized En 353 steel," Materials Science and Engineering: A Vol. 479, pp. 229-235, 2008.

[17] S. E. Vahdat, S. Nategh and S. Mirdamadi, "Microstructure and tensile properties of $45 \mathrm{WCrV7}$ tool steel after deep cryogenic treatment," Materials Science and Engineering: A Vol. 585, pp. 444-454, 2013.

[18] S. E. Vahdat, "Effect of Deep Cryogenic Processing on Tensile Toughness of 45WCrV7 Steel," International Journal of Steel Structures Vol. 14, pp. 1-8, 2014. 

Properties and Microstructure

[19] W. G. Vermeulen, P. F. Morris, A. P. d. Weijer and S. v. d. Zwaag, "Prediction of martensite start temperature using artificial neural networking," Ironmaking and Steelmaking Vol. 23, pp. 433-437, 1996. 